\title{
Deformations of temporary wooden supports used to reduce building deflections in mining areas
}

\author{
Krzysztof Gromysz ${ }^{1, *}$ \\ ${ }^{1}$ Silesian University of Technology, Faculty of Civil Engineering, Gliwice, Poland
}

\begin{abstract}
Temporary supports, consisting of a stack of wooden elements and a hydraulic jack, are used in the process of removing deflections in buildings with one to three aboveground floors in mining areas. During uneven raising, the supports are loaded monotonically, unloaded and loaded cyclically. Laboratory tests were designed for the supports. For the investigated range of loads of 0 to $400 \mathrm{kN}$, under a growing load, a linear relationship exists between a load and the change in the stack length, which signifies that the deformations of wooden elements and displacements related to their mutual interactions increase proportionally. A seemingly higher stack stiffness is seen at the beginning of the unloading process and for cyclical loads, meaning that in this phase of loading, the material deformation of the wooden elements and the jack is responsible for changing the jack length in this load phase, with a negligible presence of mutual displacements of wooden elements. The support, after being unloaded, returns to the initial position and its permanent deformations are not observed. The stiffness of a temporary support decreases as the height of the stack of wooden elements increases.
\end{abstract}

Keywords: deflected buildings, temporary wooden support, stiffness

\section{Introduction}

Temporary supports, consisting of a hydraulic jack and a stack of wooden elements, are used in the process of removing buildings deflection in buildings with up to three aboveground floors. The use of such supports is common in the mining region of Silesia, where building deflections are widespread $[1,2,3]$.

Building deflection is eliminated in several steps [1]. In the first step, piston hydraulic jacks are installed in openings made in underground floor walls. In the second step, force is excited in the jacks and the building is being torn. The tearing area is running through the load transmission points from the jack to the building (Fig. 1a). In the third step, the part of the building situated under the tearing area is elevated unevenly until a vertical position is reached. In this step, the object is revolving around an axis perpendicular to the direction of

\footnotetext{
* Corresponding author: krzysztof.gromysz@polsl.pl
} 
the deflection being eliminated [4,5]. In the case where a given jack finishes piston shift range of $200 \mathrm{~mm}$, it needs to be unloaded and underlaid. Oak wood elements with the side length of $300 \mathrm{~mm}$ and $400 \mathrm{~mm}$ and a height of $100 \mathrm{~mm}$ are used [2]. Supports have a different height because a building raising height. As a consequence, a temporary building support consists of a hydraulic jack positioned on a stack of oak elements with the height $h_{\text {wo }}$ (Fig. 1b) or consists of a jack only. The wall fragments between the raised part of the building and the part remaining in the ground are filled up in the last step, and the temporary supports are removed. Because the displacements applied are cyclical and because it is necessary to underlay the jacks in the phase of uneven raising, three support loading phases can be distinguished: the longitudinal force value is increasing monotonically, the value is decreasing and cyclical variations occur in the longitudinal force value.

The stiffness of temporary supports needs to be known when designing the straightening of a building. In particular, stiffness in the longitudinal direction is the datum used in verification calculations and when programming the extension of pistons of particular jacks. It was found many times when straightening buildings that the stiffness is not a constant value. It is thus necessary to determine such stiffness in experimental tests.

A stand for testing the stiffness of supports is presented below and experimental studies are described the purpose of which was to determine stiffness in the longitudinal direction of the jack and a stack of wooden elements and a support as a whole.

a)

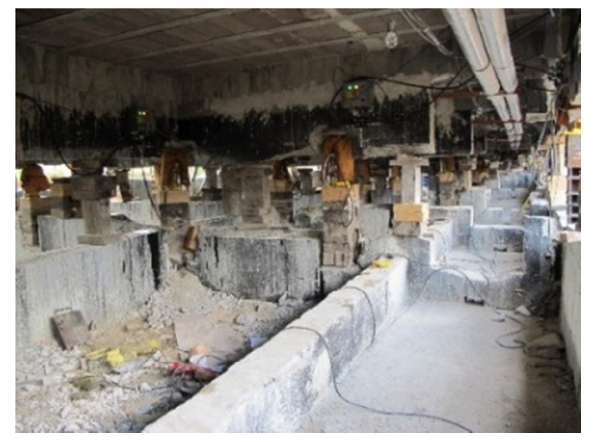

b)

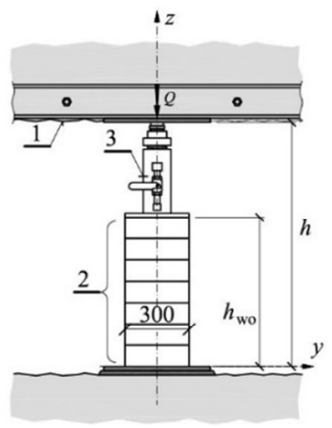

Fig. 1. Temporary supports during removal of building deflection; example of supports build in the building (a), schema of the support (b); 1 - building's tearing area, 2 - stack of wooden elements with the dimension of $300 / 400 / 100 \mathrm{~mm}, 3$ - piston hydraulic jack

\section{Tests project}

During the removal of actual buildings deflections, temporary jacks are rested on steel sheets mounted in the concrete in the building wall part situated below the tearing area (Fig. 1). The support base cannot move or rotate then. The upper part of the support is a jack piston head provided with a hinge. A static scheme of a temporary support is therefore a jack with the height $h$, loaded with vertical force $Q$ and horizontal force resulting from effects of the 2nd order or from the existence of loads in the horizontal direction (Fig. 2a). It is practically impossible to model such a scheme of a single temporary support in laboratory conditions, with the longitudinal force values $Q$ reaching $400 \mathrm{kN}$. Another test scheme for a temporary support was used for this reason. It is a freely supported element with the height $2 h$. A deformation axis of the element, considering the first buckling mode or the existence of load in the direction $y$, corresponds to a composition of an axis of two deflected supports working as a support (Fig. 2b). Under the influence of the 2 nd order effects or as a result of loading with horizontal force, the section in the middle of the height of the system, with the height $2 h$, is not rotated and corresponds to a support section of a 
support with the height $h$. The element being studied, with the height $2 h$, is, therefore, a composition of two elements with the height $h$, and a centre of symmetry of the studied system is running through the centre of its span.

a)

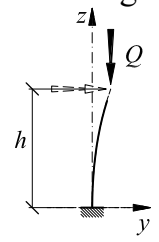

b)

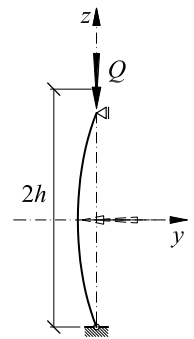

Fig. 2. Scheme of temporary support of the building with the height $h$ (a), scheme of tested system with the height $2 h(\mathrm{~b})$; force acting in $y$ direction was not considered in the tests

Laboratory tests were designed for a system with the height $2 h$, set in a horizontal position. The system being studied consists of two piston jacks placed in the direction of the axis $z$, with their bases positioned towards each other, and of a stack of fourteen rectangular elements of oak wood situated between them (Fig. 3a). The length of each element in the direction $x$ is $300 \mathrm{~mm}$ (Fig. 3b), in the direction $y-400 \mathrm{~mm}$ and $100 \mathrm{~mm}$ in the direction $z$. The direction of growth rings of all wooden elements coincides with the direction of the axis $y$. Steel plates with the dimension of $300 / 400 / 20 \mathrm{~mm}$ are situated between the bases of the jacks and a stack of wooden elements. The system was placed in a stand comprising two heads in the form of welded plate girders with a height of $440 \mathrm{~mm}$. The heads were connected with two ties, and each tie consists of two sections [200. Dynamometers were mounted between the plate girders and the jack heads (Fig. 3a).

In the tests, the system was loaded with force with the value $Q$ acting in the direction of the axis $z$, causing the system to be compressed. The force $Q$ was caused by an active jack, and the jack situated on the opposite side was a passive jack (Fig. 3a). The following was recorded during the tests: the value of the force $Q$ (Fig. 3b), variations in the length of the stack of fourteen rectangular wooden elements $\left(u_{\mathrm{wo}}\right)$ and variations in the passive jack length $\left(u_{\mathrm{ia}}\right)$.

a)

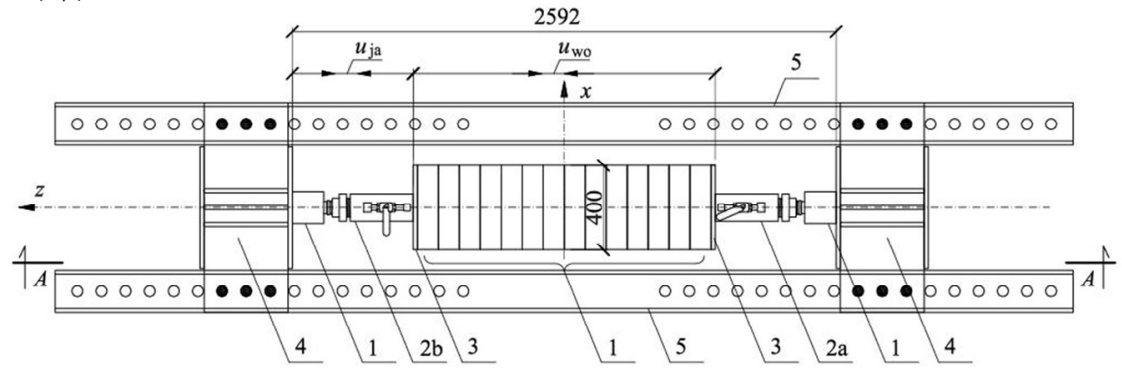

b)

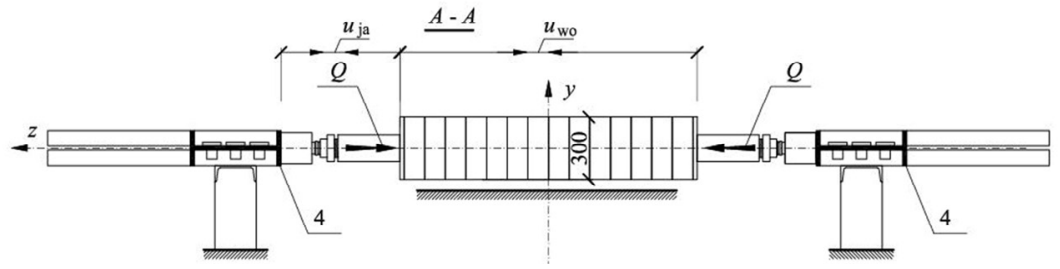

Fig. 3. Test stand and the tested system - the top view in the $y$ axis direction (a), section $A-A$ (b): $1-$ stack of fourteen rectangular wooden elements, each with dimensions of 300/400/100 mm, 2a - active hydraulic jack, $2 \mathrm{~b}$ - inactive hydraulic jack, 3 - steel sheet with dimensions of 300/400/20 mm, 4 the head of the stand, 5 - ties 


\section{Stiffness tests of the system elements}

The adopted method of loading the system was reflecting the work of the actual support when straightening the building. For this reason, at first the value of the force $Q$ was being increased monotonically from 0 to $400 \mathrm{kN}$. This part of the load was called phase $A$. After reaching the maximum deflection value, the value of the force $Q$ was being decreased in such a way so that stiffness of the system can be determined with a decreasing load and with a cyclical load. System unloading from the force value $400 \mathrm{kN}$ to zero was marked as the phase $B$ of loading. Cyclical loads with the load amplitude of $50 \mathrm{kN}$ with average forces of $375 \mathrm{kN}, 325 \mathrm{kN}, \ldots, 25 \mathrm{kN}$ were marked as the phase $C$ of loading. For this reason, the system was being unloaded as follows. The value of the force $Q$ was first decreased to 350 $\mathrm{kN}$ and then increased by $50 \mathrm{kN}$. Next, the force was decreased by $100 \mathrm{kN}$ and increased by $50 \mathrm{kN}$. Variations in the value of the force $Q$ during the test were as follows: $0 \rightarrow 400 \mathrm{kN}$ $\rightarrow 350 \mathrm{kN} \rightarrow 400 \mathrm{kN} \rightarrow 300 \mathrm{kN} \rightarrow 350 \mathrm{kN} \rightarrow 250 \mathrm{kN} \rightarrow 300 \mathrm{kN} \rightarrow 200 \mathrm{kN} \rightarrow 250 \mathrm{kN}$ $\rightarrow 150 \mathrm{kN} \rightarrow 200 \mathrm{kN} \rightarrow 100 \mathrm{kN} \rightarrow 150 \mathrm{kN} \rightarrow 50 \mathrm{kN} \rightarrow 100 \mathrm{kN} \rightarrow 0 \mathrm{kN} \rightarrow 50 \mathrm{kN} \rightarrow 0$. Table 1 lists loading phases with description of variations in the $Q$ force value. The load was applied with a speed of $1 \mathrm{kN} / \mathrm{s}$. The speed of load applying was small and didn't affect the rigidity of support.

A chart showing variations in the length $u_{\text {wo }}$ of the stack of fourteen rectangular wooden elements under the influence of the changing value of the force $Q$, which was recorded every about $2 \mathrm{kN}$, is given in Fig. 4a. The phases of the monotonically growing load (phase $A$ ), falling load (phase $B$ ) and cyclical load (phase $C$ ) can be clearly distinguished in the figure. Figure $4 \mathrm{~b}$ presents variations in the length $u_{\mathrm{ja}}$ of the passive jack depending on the value of the force $Q$.

Table 1. Load phases of the system

\begin{tabular}{|c|c|}
\hline Load phase & Change of $Q$ force value \\
\hline$A$ - monotonically growing & $0 \rightarrow 400 \mathrm{kN}$ \\
\hline \multirow{2}{*}{$B$ - falling } & $400 \mathrm{kN} \rightarrow 350 \mathrm{kN} \rightarrow 350 \mathrm{kN} \rightarrow 250 \mathrm{kN} \rightarrow 250 \mathrm{kN} \rightarrow 150 \mathrm{kN} \rightarrow$ \\
& $150 \mathrm{kN} \rightarrow 50 \mathrm{kN} \rightarrow 50 \mathrm{kN} \rightarrow 0$ \\
\hline & $350 \mathrm{kN} \rightarrow 400 \mathrm{kN} \rightarrow 350 \mathrm{kN} ; 300 \mathrm{kN} \rightarrow 350 \mathrm{kN} \rightarrow 300 \mathrm{kN} ;$ \\
& $250 \mathrm{kN} \rightarrow 300 \mathrm{kN} \rightarrow 250 \mathrm{kN} ; 200 \mathrm{kN} \rightarrow 250 \mathrm{kN} \rightarrow 200 \mathrm{kN} ;$ \\
& $150 \mathrm{kN} \rightarrow 200 \mathrm{kN} \rightarrow 150 \mathrm{kN} ; 100 \mathrm{kN} \rightarrow 150 \mathrm{kN} \rightarrow 100 \mathrm{kN} ;$ \\
& $50 \mathrm{kN} \rightarrow 100 \mathrm{kN} \rightarrow 50 \mathrm{kN} ;$ \\
\hline
\end{tabular}

a)

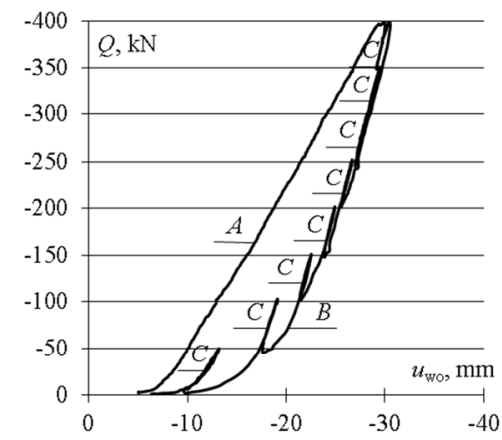

b)

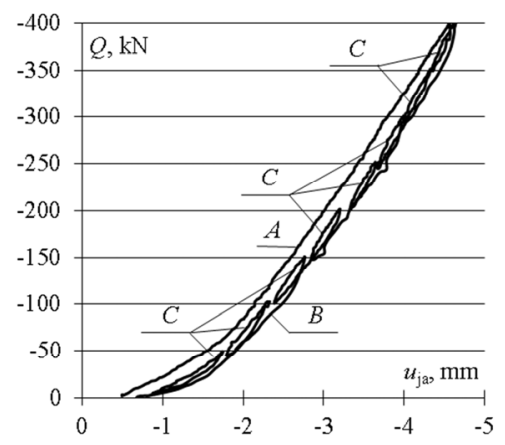

Fig. 4. Phases $A, B, C$ of system loading $Q-u_{\mathrm{wo}}$ relationship (a), $Q-u_{\mathrm{ja}}$ relationship (b)

The following method was used of determination of the stiffness of a stack of wooden elements depending on the load phase. First, the polynomials were determined with the method of least squares describing the load - stack length variation relations for particular 
phases. Next, functions calculating the stiffness of stacks as the derivatives of such polynomials were calculated.

For a monotonic load (phase $A$ ), a satisfactory description of the $Q=Q\left(u_{\text {wo }}\right)$ relationship was obtained with a polynomial of first degree. On the other hand, for the unload (phase $B$ ) and cyclical load (phase $C$ ), a satisfactory description of the $Q=Q\left(u_{\text {wo }}\right)$ relationship was obtained with a polynomial of fourth degree. The values of the determination coefficient $R^{2}$ of all approximations were not lower than 0.99, denoting that the tests results were well described. The determined $Q\left(u_{\text {wo }}\right)$ polynomials, for the stack of elements, with the corresponding values of $R^{2}$, are listed in Table 2 . The polynomials describing the changes of $Q=$ $Q\left(u_{\text {wo }}\right)$ are presented graphically in Figure 5a. According to the adopted management procedure, the stiffness of a stack - corresponding to a given load phase - was determined as a polynomial derivative

$$
k_{w o}=\frac{d Q}{d u_{w o}}
$$

a)

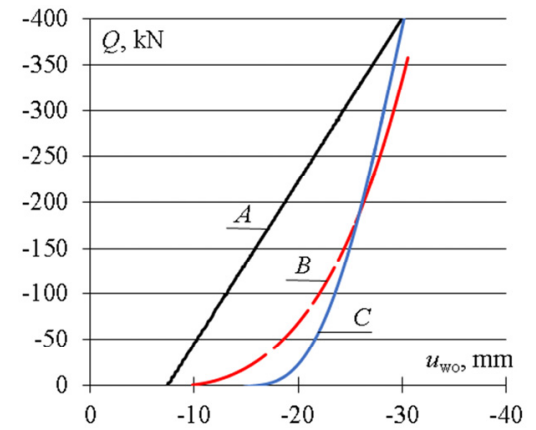

b)

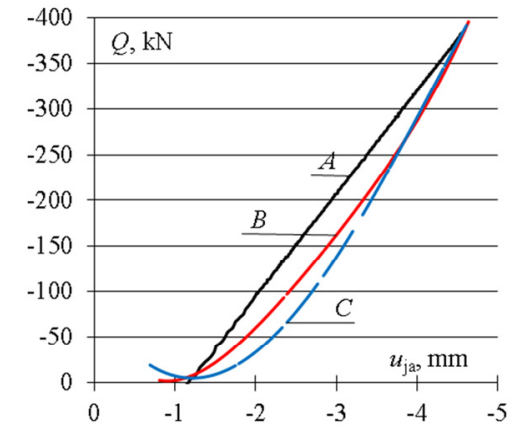

Fig. 5 Approximation of the force - displacement relationship - $Q\left(u_{\mathrm{wo}}\right)(\mathrm{a}), Q\left(u_{\mathrm{ja}}\right)(\mathrm{b})$

For a monotonically growing load, stiffness of a $1400 \mathrm{~mm}$ high stack is described, with sufficient accuracy, by the constant value $k_{\mathrm{wo}}=17.718 \mathrm{MN} / \mathrm{m}$. For the unloading phase and cyclical loads, stack stiffness depends on the value of the loading force $Q$. As the value of this force is falling, stack stiffness decreases. For a maximum load of $400 \mathrm{kN}$, stack stiffness is about $50 \mathrm{MN} / \mathrm{m}$. As the value of the loading force decreases, stack stiffness decreases to $3 \mathrm{MN} / \mathrm{m}$ with the force $Q$ value of nearly zero. A decrease in stiffness, along with a decrease in the load, is higher for a cyclical load. Figure 6a shows a variation in stack stiffness for three types of load.

a)

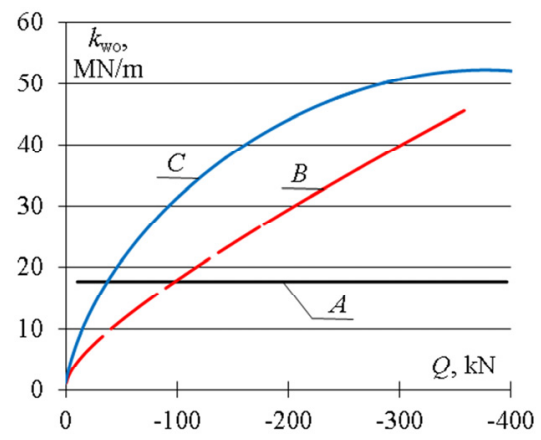

b)

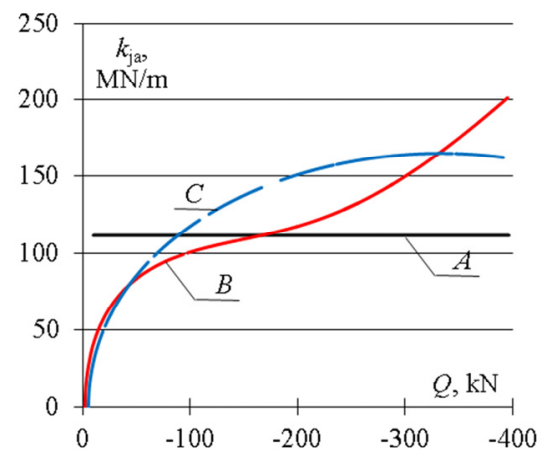

Fig. 6. Stiffness as a parameter depending on the loading force value and load phase - stiffness of stack of wooden elements (a), stiffness of hydraulic jack (b) 
An analogous analysis was made for a variation in the length $u_{\mathrm{ja}}$ of a passive jack. The relations $Q=Q\left(u_{\mathrm{ja}}\right)$ were first described with polynomials. For a monotonic load (phase $A$ ), a satisfactory description was obtained with a polynomial of first degree. On the other hand, for the falling load (phase $B$ ) and cyclical load (phase $C$ ), a satisfactory description of the relationship $Q=Q\left(u_{\mathrm{ja}}\right)$ was obtained with a polynomial of fourth degree. The values of coefficients $R^{2}$ of all approximations were not lower than 0.98 . The determined $Q\left(u_{\mathrm{ja}}\right)$ polynomials, with the corresponding values of $R^{2}$, are listed in Table 3 . The polynomials describing the changes $Q=Q\left(u_{\mathrm{ja}}\right)$ are presented graphically in Figure $5 \mathrm{~b}$. The jack stiffness, corresponding to a given load phase, was determined as a polynomial derivative and listed in Table 3 and shown graphically in Figure $6 \mathrm{~b}$.

For a monotonically growing load, stiffness of a $1400 \mathrm{~mm}$ high stack is described, with sufficient accuracy, by the constant value $k_{\mathrm{wo}}=17.718 \mathrm{MN} / \mathrm{m}$. For the unloading phase and cyclical loads, stack stiffness depends on the value of the loading force $Q$. As the value of this force is falling, stack stiffness decreases. For a maximum load of $400 \mathrm{kN}$, stack stiffness is about $50 \mathrm{MN} / \mathrm{m}$. As the value of the loading force decreases, stack stiffness decreases to $3 \mathrm{MN} / \mathrm{m}$ with the force $Q$ value of nearly zero. A decrease in stiffness, along with a decrease in the load, is higher for a cyclical load. Figure 6a shows a variation in stack stiffness for three types of load.

Table 2. Approximation of the $Q-u_{\mathrm{wo}}$ relationship and function describing the stiffness of the stack of rectangular wooden elements

\begin{tabular}{|l|c|}
\hline Load type & $\begin{array}{l}\text { Approximation of the load } Q=Q\left(u_{w o}\right) ; R^{2} \\
\text { Description of stiffness } k_{w o}=d Q / d u_{w o}\end{array}$ \\
\hline $\begin{array}{l}\text { A - mono- } \\
\text { tonically } \\
\text { growing }\end{array}$ & $\begin{array}{c}Q=17,718 u_{w o}+129,87 ; R^{2}=0,999 \\
k_{w o}=17,718\end{array}$ \\
\hline B - falling & $\begin{array}{c}Q=-0,0006 u_{w o}^{4}-0,0201 u_{w o}^{3}-0,6955 u_{w o}^{2}-9,023 u_{w o}-35,06 ; R^{2}=0,999 \\
k_{w o}=0,0016 u_{w o}^{3}+0,0603 u_{w o}^{2}-1,319 u_{w o}-9,023\end{array}$ \\
\hline C - cyclical & $\begin{array}{c}Q=-0,0009 u_{w o}^{4}+0,815 u_{w o}^{3}+24,963 u_{w o}^{2}+321,55 u_{w o}+1503,3 ; R^{2}=0,9986 \\
k_{w o}=0,036 u_{w o}^{3}+2,445 u_{w o}^{2}+49,926 u_{w o}+321,55\end{array}$ \\
\hline
\end{tabular}

An analogous analysis was made for a variation in the length $u_{\mathrm{ja}}$ of a passive jack. The relations $Q=Q\left(u_{\mathrm{ja}}\right)$ were first described with polynomials. For a monotonic load (phase $A$ ), a satisfactory description was obtained with a polynomial of first degree. On the other hand, for the falling load (phase $B$ ) and cyclical load (phase $C$ ), a satisfactory description of the relationship $Q=Q\left(u_{\mathrm{ja}}\right)$ was obtained with a polynomial of fourth degree. The values of coefficients $R^{2}$ of all approximations were not lower than 0.98 . The determined $Q\left(u_{\mathrm{ja}}\right)$ polynomials, with the corresponding values of $R^{2}$, are listed in Table 3 . The polynomials describing the changes $Q=Q\left(u_{\mathrm{ja}}\right)$ are presented graphically in Figure 5b. The jack stiffness, corresponding to a given load phase, was determined as a polynomial derivative and listed in Table 3 and shown graphically in Figure 6 b.

Table 3. Approximation of the $Q-u_{\mathrm{ja}}$ relationship and function describing the stiffness of hydraulic jack

\begin{tabular}{|l|l|}
\hline Load type & $\begin{array}{l}\text { Approximation of the load } Q=Q\left(u_{j a}\right) ; R^{2} \\
\text { Description of stiffness } k_{j a}=d Q / d u_{j a}\end{array}$ \\
\hline $\begin{array}{l}\text { A - mono- } \\
\text { tonically } \\
\text { growing }\end{array}$ & $Q=111,68 u_{j a}+126,04 ; R^{2}=0,984$ \\
\hline
\end{tabular}




\begin{tabular}{|l|c|}
\hline B - falling & $\begin{array}{c}Q=-2,6883 U_{j a}^{4}-30,459 u_{j a}^{3}-137,48 u_{j a}^{2}-181,70 u_{j a}-74,90 ; R^{2}=0,999 \\
k_{j a}=-10,7532 u_{j a}^{3}-91,377 u_{j a}^{2}-274,96 u_{j a}-181,70\end{array}$ \\
\hline C - cyclical & $\begin{array}{c}Q=0,2661 u_{j a}^{4}-2,4599 u_{j a}^{3}-60,477 u_{j a}^{2}-133,99 u_{j a}-83,953 ; R^{2}=0,999 \\
k_{j a}=1,0644 u_{j a}^{2}-7,3797 u_{j a}^{2}-120,954 u_{j a}-133,99\end{array}$ \\
\hline
\end{tabular}

For a monotonically growing load, jack stiffness is described, with sufficient accuracy, by the constant value $k_{\mathrm{ja}}=111.68 \mathrm{MN} / \mathrm{m}$. For the unloading phase and cyclical loads, jack stiffness depends on the value of the loading force $Q$. As the value of the force $Q$ is falling, jack stiffness decreases. For a maximum load of $400 \mathrm{kN}$, its stiffness is about 150 $\mathrm{MN} / \mathrm{m}$, and as the load is falling, jack stiffness decreases to nearly zero.

\section{Determination of stiffness of temporary support in longitudinal direction}

The stiffness of the stack of wooden elements decreases along with its height. If the stiffness of the stack with a height of $1400 \mathrm{~mm}$ is known, the stiffness of the stack with the height $h$ (Fig. 7a) can be determined from the following relationship:

$$
k_{w o, h}=k_{w o} \frac{1400}{h}
$$

The total variation in the length of a temporary support is a sum of variation in the length of displacements of the stack of wooden elements and the jack. As a result, a model of a temporary support is represented by a serial connection of the stack of wooden elements and the jack (Fig. 7b). Considering the above, the stiffness $k$ of the whole support is determined from the following relationship:

$$
k=\frac{k_{w o, h} k_{j a}}{k_{w o, h}+k_{j a}}
$$

Figures $7 \mathrm{c}-7 \mathrm{~d}$ show charts presenting support stiffness in phases $A, B, C$ depending on the height $h_{\mathrm{wo}}$ of the stack of wooden elements and for the value of the force $Q=100 \mathrm{kN}$, $200 \mathrm{kN}, 300 \mathrm{kN}$.

a)

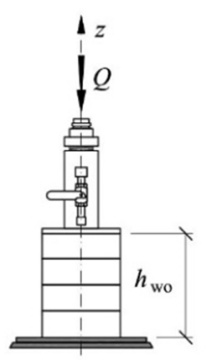

b)

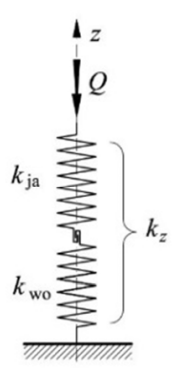

c)

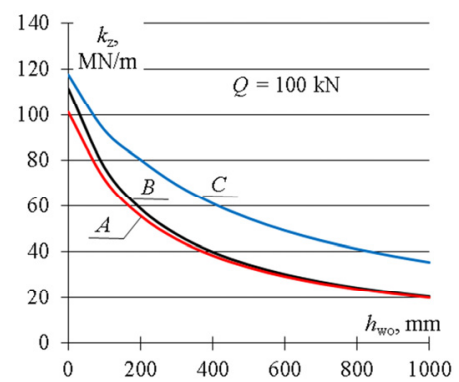


d)

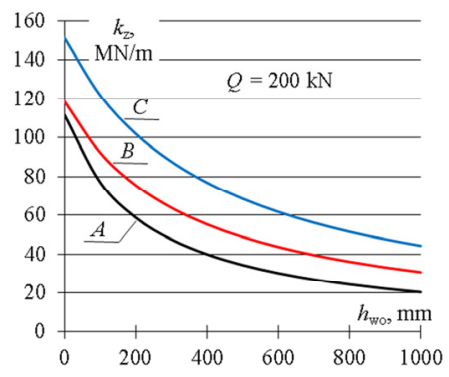

e)

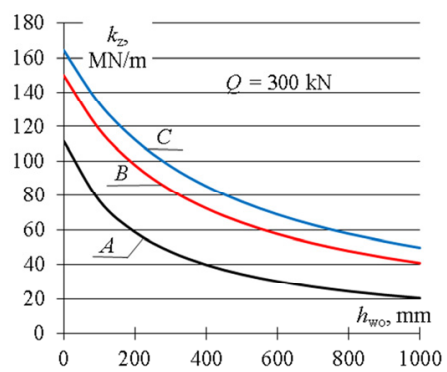

Fig. 7. Stiffness of temporary supports consisting of hydraulic jack and stack of wooden elements as depending on the height $h_{\text {wo }}$ of the stack - sketch of the support (a), scheme of the support as serial connection of elements with stiffness $k_{\text {wo }}$ and $k_{\text {ja }}(\mathrm{b})$, stiffness of the support depending on the height $h_{\text {wo }}$ of the stack for the load force $Q(Q=100 \mathrm{kN}, 200 \mathrm{kN}, 300 \mathrm{kN})(\mathrm{c}, \mathrm{d}, \mathrm{e})$

The stiffness of a temporary support is decreasing along with the increased height of the stack of wooden elements. This stiffness is decreased by about three times if four wooden elements with the total height of $400 \mathrm{~mm}$ are installed. For the values of the load force of above $100 \mathrm{kN}$, support stiffness for cyclical loading and unloading is higher than for monotonical loading.

\section{Conclusions}

The stiffness of temporary supports in the longitudinal direction can be calculated as the stiffness of a system consisting of a serially connected jack and a stack of wooden elements. The stiffness of a temporary support is declining along with the increased height of the stack of wooden elements.

In the cycle of monotonic increase of the load, the support has the stiffness of 111 $\mathrm{MN} / \mathrm{m}$ in the case where the support is represented by a jack itself. This stiffness is decreasing to $22 \mathrm{MN} / \mathrm{m}$ when a stack of the wooden elements mounted under the jack is $900 \mathrm{~mm}$.

For a cyclical load with the maximum value of $400 \mathrm{kN}$, the support stiffness - in the absence of wooden elements - is approx. $160 \mathrm{MN} / \mathrm{m}$, and with the height of the wooden elements stack of $900 \mathrm{~mm}$, the stiffness decreases to $45 \mathrm{MN} / \mathrm{m}$.

\section{References}

1. Gromysz K., Methods of Removing Buildings Deflection Used In Poland. IOP Conf. Ser.: Mater. Sci. Eng. 245032096 (2017)

2. Gromysz K., Kowalski A., Mika W., Niemiec T., Repair of historical wooden church situated on mining area. Mining Review No. 3: p. 14-20 .(2015)

3. Kawulok M., Evaluation of functional properties of buildings considering mining impacts. Publishing House of the Building Research Institute, Warsaw (2000)

4. Kwiatek J. et al., Protection of building structures on mining areas. Publishing House of the Central Mining Institute, Katowice (1997)

5. Wyleżoł M., Determination of measurable deflection of buildings in the aspect of their designing. Collective work edited by K. Gromysz and R. Domagała. Outline of selected issues of Civil Engineering. Publishing House of the Silesian University of Technology: 191-198 (2017)

6. Gromysz K., Niemiec T., Selected issues in straightening the vertically deflected building structures". 3rd Scientific and Training Conference. Safety and protection of building structures on mining areas, Ustroń-Zawodzie, October 2010, Scientific works of the Central Mining Institute (GiG), Katowice: 43-65 (2010) 